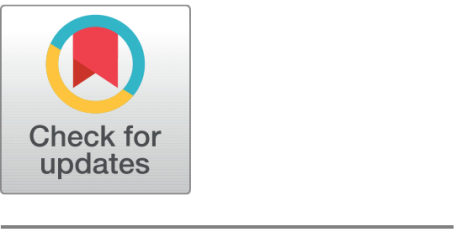

OPEN ACCESS

Received: 22.10 .2020

Accepted: 01.01.2021

Published: 05.02.2021

Citation: Karunamoorthy $P$, Rajesh EM, Ravichandran B, Venugopal D, Gunasekaran K, Naina H, Ambikapathy M (2021) Pulmonary function impairment and lung infections among tannery workers in Southern India. Indian Journal of Science and Technology 14(4): 382-392. https://doi.org/ 10.17485/IJST/V14i4.1869

* Corresponding author.

Tel: 09483525382

ravichandranrohc@gmail.com

Funding: ICMR-National Institute of Occupational Health, Ahmedabad

Competing Interests: None

Copyright: @ 2021 Karunamoorthy et al. This is an open access article distributed under the terms of the Creative Commons Attribution License, which permits unrestricted use, distribution, and reproduction in any medium, provided the original author and source are credited.

Published By Indian Society for Education and Environment (iSee)

ISSN

Print: 0974-6846

Electronic: 0974-5645

\section{Pulmonary function impairment and lung infections among tannery workers in Southern India}

\author{
Panjakumar Karunamoorthy ${ }^{1}$, Embiranahalli Mani Rajesh², \\ Beerappa Ravichandran ${ }^{1 *}$, Dhananjayan Venugopal', Karthik Gunasekaran ${ }^{3}$, \\ Hariharan Naina ${ }^{4}$, Mala Ambikapathy ${ }^{1}$ \\ 1 Industrial Hygiene \& Toxicology, ICMR-Regional Occupational Health Centre (Southern), \\ Kannamangala PO, Devanahalli Taluk, Bangalore, 562110, India. Tel.: 09483525382 \\ 2 Department of Microbiology, PSG College of Arts and Science, Civil Aerodrome, \\ Coimbatore, 641014, India \\ 3 Department of Community Medicine, Christian Medical College, Vellore, 632004, India \\ 4 Factory Medical Officer, Asian Paints, Kanchipuram, 602105, India
}

\section{Abstract}

Background/Objectives: Tannery workers are prone to lung diseases due to hazardous operational conditions. Therefore, the present study was designed to investigate the respiratory morbidities and lung infections among tannery workers. Methods: This study included 110 tannery workers (83 male and 27 female). Pulmonary Function Test (PFT) was carried out among 53 workers. Direct microscopic examination and standard microbial culture were carried out to identify lung infections from clinical samples. Statistical analyses were carried using the SPSS software, version 26. Findings: Pulmonary Function Test (PFT) revealed severe restrictive, moderate restrictive and small airway obstruction among $16.9 \%, 18.9 \%$ and $11.3 \%$ of workers respectively. PPE usage was reported among $68 \%$ of the workers. Only $3.6 \%$ of the subjects reported being used face masks during work. The respiratory symptoms viz; cold \& cough (44.5\%), asthma (2.7\%), wheezing (14.5\%), shortness of breath (17.3\%) and chronic bronchitis (3.6\%) were noted among study subjects. A significant association was found between altered PFT values and the risk factors such as working sections and lack of PPE usage $(p<0.05)$. Bacterial lung infections viz; Klebsiella pneumonia, Streptococcus pneumonia, Staphylococcus aureus and fungal infections viz; Candida albicans, Aspergillus niger and Aspergillus flavus were identified. Confounding factors of working sections and lack of PPE usage found to influence the PFT parameters. Applications: The study highlights the constant infectious hazards at the workplace. Frequent health monitoring, workplace monitoring, engineering controls and PPE use are mandate to curtail respiratory morbidity among tannery workers

Keywords: Tannery workers; occupational lung disorder; Pulmonary function test; lung infections 


\section{Introduction}

Occupational lung diseases are an under-recognition, under-reported in developing countries ${ }^{(1)}$. Respiratory diseases are lifethreatening health problems to the workers, most are work-related. International Labour Organization (ILO) stated workrelated diseases $(30 \%)$ and death (10-20\%) worldwide ${ }^{(2)}$. The working environment contributes to a high burden of respiratory morbidity in lower and middle-income countries ${ }^{(3)}$. Tannery industries are well-known potential hazard to the environment as well as to the working population in this sector. The health conditions of tannery employees are adversely affected by the working environment ${ }^{(4)}$. The leather production process involved three stages namely pre-tanning (preparation of hide for tanning), tanning (vegetable tanning or chrome tanning process) and post-tanning (finishing process). The preparatory stages in tanning process pose a risk of zoonotic infections from the raw animal hides. Fungal and bacterial colonies grown on leather and on the liquors in tannery industry pose an infectious hazard to the tanners ${ }^{(5)}$. The intensive use of chemicals, manual processes, wet-humid environment and machinery operations in tannery industries pose an occupational hazard to the workers engaged in these environments if failed to adopt appropriate personal protective equipment(PPE) and other safety measures ${ }^{(6)}$.

Worldwide millions of workers in tanneries are exposed to toxic chromium compounds which impose health risk assessment among this vulnerable group ${ }^{(7)}$. Occupational exposure to chromium occurs through inhalation, absorption, and ingestion. The primary health impacts of chromium are the respiratory, gastrointestinal, reproductive systems ${ }^{(8)}$ and weakened immune systems ${ }^{(9)}$. Exposure to chromium trioxide can result in the damage to the nasal septum and lower respiratory tract by ulceration and perforation ${ }^{(10,11)}$ that leads to bronchitis, asthma, pulmonary edema and bronchospasms ${ }^{(12)}$. Depending on the workplace settings, there are numerous health risks, viz; musculoskeletal disorders, respiratory problems, skin diseases, infectious diseases, cancers, physical injuries and ocular problems are recorded among tannery workers ${ }^{(13)}$. Respiratory disorders such as asthma, chronic bronchitis, allergic bronchitis, sinusitis and pulmonary tuberculosis were mainly responsible for higher morbidity among the tannery workers ${ }^{(9,14)}$.

During the tanning process, airborne pathogens present in the indoor tannery environment may serve as constant infectious hazards ${ }^{(15)}$. In the present critical situation exposure to bioaerosols in occupational settings as well as in residential environments has drawn significant alertness. The airborne microorganisms like bacteria, viruses and fungal spores present in the working environment can be transmitted to humans via inhalation, dermal contact and ingestion. The bioaerosols in an indoor environment consisted of microbes, metabolites of microbes, heat-resistant spores, mycotoxin and endotoxins. Personal exposure to bio-aerosols in an indoor environment has the health impacts such as infections, allergies, lower and upper respiratory tract inflammations, and deficits in lung function ${ }^{(16,17)}$. The severity of the health effects may vary depending on the individual's characters including allergen sensitivity, immunity and duration of exposure to the contaminants ${ }^{(15)}$.

The most often reported fungi in indoor tannery industries are Aspergillus spp., Penicillium spp., Alternaria spp and Cladosporium $s p p^{(12)}$. Tetanus, anthrax, leptospirosis, epizootic aphtha, $\mathrm{Q}$ fever, and brucellosis are the diseases occurred among butchers and slaughterhouse workers, those who have contacted during handling of animal and animal hides ${ }^{(18)}$. Fungal spores are widespread in nature and are a severe threat to community health in indoor environments. Development of allergies, asthma and respiratory infections were correlated with long-term exposure to fungi in tanning environment. The allergic manifestations induced by fungi been documented widely are asthma, rhinitis, allergic bronchopulmonary mycoses and hypersensitivity pneumonitis ${ }^{(19)}$. There are clusters of tannery industries in southern part of India and nearly one lakh people are working in these industries ${ }^{(20)}$. However, there is a paucity concerning information on respiratory morbidities among tannery workers in south India. Therefore, the present study is designed to investigate the respiratory morbidities and bioaerosol exposure associated with bacterial and fungal respiratory infections among tannery workers in the southern state, Tamil Nadu, India.

\section{Materials and methods}

\subsection{Study Area}

Vellore and surrounding districts Ranipet and Tiruppatur are the major locations having dense leather processing industries in Tamil Nadu, with an estimated number of 50,000 tannery workers. Among these the Ranipet and surrounding areas have more tannery industries; therefore the present study was carried out in this region. The medical camp and face to face interview were conducted at Otteri village, located in Ranipet district, Tamil Nadu. 


\subsection{Sample size and study population}

Institutional ethics committee approval was obtained prior to the initiation of the study. A total of 110 tannery workers consist of 83 males and 27 females serving at different tannery sections who volunteered to participate were included in this study.

The sample size was calculated by using the formula,

$$
\text { Sample size } \mathbf{n}=\frac{\left(\mathbf{Z}_{\alpha / 2}+\mathbf{Z}_{8}\right)^{2} \mathbf{P q}}{\mathbf{d}^{2}}
$$

With the level of significance $5 \%$, power $90 \%$, prevalence rate $27 \%{ }^{[13]}$ and the assumed error was $0.135(\mathrm{~d}=\mathrm{p} / 2)$. Therefore, the calculated sample size was 112. In this cross-sectional study 110 subjects have been covered to achieve the objectives with the dropout of 2 subjects.

The workers who were involved in the leather tanning process such as the pre-tanning process, tanning and post tanning were selected and interviewed. Depending upon the work activity the workers are categorized into three groups; Pre-tanning section- those involved in sorting, curing, storage of hides, soaking, un-hairing, liming, deliming, bating, pickilng and beam house activities; Tanning section- those involved in tanning, sammying, retanning, shaving and fatliquoring activities; Posttanning- those involved in drying, dyeing, oiling, brushing, padding, buffing, roller coating, polishing, plating and ironing activities.

\subsection{Questionnaire and respiratory symptoms}

A cross-sectional and descriptive study was carried out among the workers employed in different tanneries. A face-toface interview was conducted using pre-designed questionnaire, prepared in English and in the local language Tamil. The questionnaire details consisted of demographic characteristics, personal habits, occupational details and health status of workers. The respiratory symptoms evaluated were acute and chronic cough with or without phlegm, shortness of breath, wheezing, chronic bronchitis, asthma, family history with tuberculosis and respiratory-related health complaints. Informed consent was obtained from the participants prior to the study.

\subsection{Sampling and culture}

Out of 110 study subjects, the early sputum samples $(n=19)$ and throat swabs were collected only from the subjects who suffered from productive cough and respiratory symptoms. Ziehl-Neelsen stain was performed to identify Mycobacterium tuberculosis from clinical samples. The clinical samples are subjected to direct microscopic examination and microbial culture to identify the genus and species of causative microbial agents. Isolation of bacteria and fungi was carried out according to standard culture techniques ${ }^{(21)}$. Fungal isolation was achieved by inoculating samples into Sabouraud dextrose agar (SDA) containing cycloheximide and chloramphenicol. The fungal cultural characteristics and biochemical characteristics were evaluated. The microscopic examination of fungal growth was carried out using lactophenol cotton blue (LPCB) stain, cultural characteristics such as colony texture, rate of growth and pigmentation production of the front and the reverse side of the culture plates were evaluated. Bacterial culture was performed using Blood agar (BA) (contained 5\% sheep blood) and MacConkey agar. Smear study, cultural characteristics and biochemical assays were performed to identify the genus and species of isolates.

\subsection{Pulmonary Function Tests (PFT)}

Pulmonary Function Test (PFT) was carried out among 53 tannery workers excluding the subjects who suffered from asthma, haemoptysis, myocardial infarction and undergone recent surgery. A precalibrated portable spirometer (VitalographPneumotrac, US) was used to record the spirometric functions. Trained personal performed the PFT under the supervision of a medical officer. The spirometer was adjusted with gender, age, height and weight for each subject and tests were performed according to standard procedure. The PFT was repeated to obtain higher values. Forced Vital Capacity (FVC), Forced Expiratory Volume (FEV), Peak Expiratory Flow (PEF) and the ratio of FEV1/FVC were the parameters evaluated. Height and weight were measured by stadiometer, random blood sugar (RBS) was measured by one touch glucometer and blood pressure was measured by sphygmomanometer.

\subsection{Statistical analysis}

All the statistical analyses were done using the SPSS software, version 26. The Kruskal Wallis analysis was performed to know the variation in non-symmetric PFT values among the groups. Binary logistic regression analysis was performed to determine 
the influence of age, education status, working section, year of experience, BMI, smoking, alcohol and PPE usage on PFT parameters. The $\mathrm{p}$-values less than 0.05 were considered significant.

\section{Results and Discussion}

\subsection{Demographic characteristics}

The demographic characteristics and occupational details of the workers were presented in Table 1 . The mean age of the workers was $43.8 \pm 9.6$ years and the mean height $(\mathrm{cm})$ and weight $(\mathrm{kg})$ of the workers were $162.3 \pm 6.5$ and $59.3 \pm 9.7$ respectively. The mean work experience of the workers in the tannery industry was 15 years, ranging from 1-40 years. The exposure hours in the tanning process was 5-12 hours/day. The BMI of the workers revealed $4.5 \%$ of them were obese and $23.6 \%$ had overweight. The mean RBS and systolic blood pressure was $159.2 \pm 86.3 \mathrm{gm} / \mathrm{dl}$ and $134.8 \pm 21.3 \mathrm{mmHg}$ respectively. The distribution of workers according to their working departments was; pre-tanning section- 49, tanning section-37 and post tanning section -24. The usage of Personal Protective Equipment (PPE) was reported by $68 \%$ of workers, whereas $32 \%$ of the workers did not use any kind of PPE. Only 3.6\% of the subjects reported being used face masks while work, tobacco chewing habit observed among $8.1 \%$ subjects and smoking habits observed among $22.7 \%$ subjects alcoholic addiction observed among $35.4 \%$ subjects.

Table 1. Demographic characters and occupational details of tannery workers

\begin{tabular}{|c|c|c|}
\hline \multicolumn{2}{|c|}{ Variables } & \multirow{2}{*}{$\begin{array}{l}\text { Tannery workers }(\mathrm{n}=110) \\
43.8 \pm 9.6\end{array}$} \\
\hline Age & Mean \pm SD & \\
\hline Height $(\mathrm{cm})$ & Mean \pm SD & $162.3 \pm 6.5$ \\
\hline Weight (kg) & Mean \pm SD & $59.3 \pm 9.7$ \\
\hline \multirow[t]{2}{*}{ Gender } & Male & $83(75.4)$ \\
\hline & Female & $27(24.5)$ \\
\hline \multirow[t]{5}{*}{ BMI kg/m2 (18.5-24.9kg/m2) } & Mean \pm SD & $22.6 \pm 4$ \\
\hline & Underweight & $18(16.4)$ \\
\hline & Normal & $61(55.4)$ \\
\hline & Overweight & $26(23.6)$ \\
\hline & Obesity & $5(4.5)$ \\
\hline Random Blood sugar (gm/dl) & Mean \pm SD & $159.2 \pm 86.3$ \\
\hline \multirow[t]{2}{*}{ Blood pressure (mmHg) } & Systolic & $134.8 \pm 21.3$ \\
\hline & Diastolic & $84.25 \pm 12.5$ \\
\hline Tobacco chewing habit & Yes & $9(8.1)$ \\
\hline Smoking habits & Yes & $25(22.7)$ \\
\hline Alcohol consumption & Yes & $39(35.4)$ \\
\hline \multirow[t]{3}{*}{ Working Section } & Pre tanning & $49(44.5)$ \\
\hline & Tanning & $37(33.6)$ \\
\hline & Post Tanning & $24(24.5)$ \\
\hline \multirow[t]{2}{*}{ Work Experience (Years) } & Mean \pm SD & $15.4 \pm 9.6$ \\
\hline & Range & $1-40$ \\
\hline Exposure Hours & Range /per day & $5-12$ \\
\hline \multirow[t]{3}{*}{ PPE Usage } & Users & $75(68)$ \\
\hline & Non users & $35(31.8)$ \\
\hline & Face mask users & $4(3.6)$ \\
\hline
\end{tabular}

Parenthesis indicates percentage (\%)

\subsection{Lung diseases \& health complaints}

Respiratory symptoms and other health complaints noted among tannery workers of different departments were presented in Table 2. The clinical symptoms of frequent cold \& cough $44.5 \%$, productive cough $17.2 \%$, dry cough $12.7 \%$, chest pain while cough $7.2 \%$, wheezing $14.5 \%$, shortness of breath $17.3 \%$, asthma $2.7 \%$, lung infections $11.8 \%$ and chronic lung diseases $3.6 \%$ were found among study subjects. Diabetes mellitus $19.9 \%$ and hypertension $11.8 \%$ were found among study subjects. The respiratory diseases noted among the study subjects were represented in Figure 1. The prevalence rate of respiratory diseases 
was found insignificant among the groups.

Table 2. Respiratory morbidity and chronic illness among tannery workers according to their working section

\begin{tabular}{|c|c|c|c|c|c|}
\hline Variables & Pre-tanning $(\mathrm{n}=49)$ & Tanning $(n=37)$ & Post tanning $(\mathrm{n}=24)$ & Total $(n=110)$ & $\mathrm{p}$-value \\
\hline Cold \& cough & $25(51)$ & $17(45.9)$ & $7(29.6)$ & $49(44.5)$ & 0.21 \\
\hline Cough with phlegm & $10(20.4)$ & $7(18.9)$ & $2(8.3)$ & $19(17.2)$ & 0.50 \\
\hline Cough without phlegm & $6(12.2)$ & $6(16.2)$ & $2(8.3)$ & $14(12.7)$ & 0.832 \\
\hline Chest pain while cough & $6(12.2)$ & $1(2.7)$ & $1(4.1)$ & $8(7.2)$ & 0.19 \\
\hline Wheezing & $10(20.4)$ & $5(13.5)$ & $1(4.1)$ & $16(14.5)$ & 0.18 \\
\hline Shortness of breath & $9(18.3)$ & $8(21.6)$ & $2(8.3)$ & $19(17.3)$ & 0.39 \\
\hline Respiratory infections & $3(6.1)$ & $2(5.4)$ & $1(4.1)$ & $6(5.4)$ & 0.94 \\
\hline Chronic lung diseases & $1(2)$ & $3(8.1)$ & 0 & $4(3.6)$ & NA \\
\hline Asthma & $1(2)$ & $2(5.4)$ & 0 & $3(2.7)$ & NA \\
\hline Lung infections & $7(14.2)$ & $5(13.5)$ & $1(4.1)$ & $13(11.8)$ & 0.42 \\
\hline Diabetes & $7(14.2)$ & $9(24.3)$ & $5(20.8)$ & $21(19.9)$ & 0.49 \\
\hline Hypertension & $6(12.2)$ & $5(13.5)$ & $2(8.3)$ & $13(11.8)$ & 0.82 \\
\hline
\end{tabular}

${ }^{*}$ parenthesis indicates percentage $(\%)$

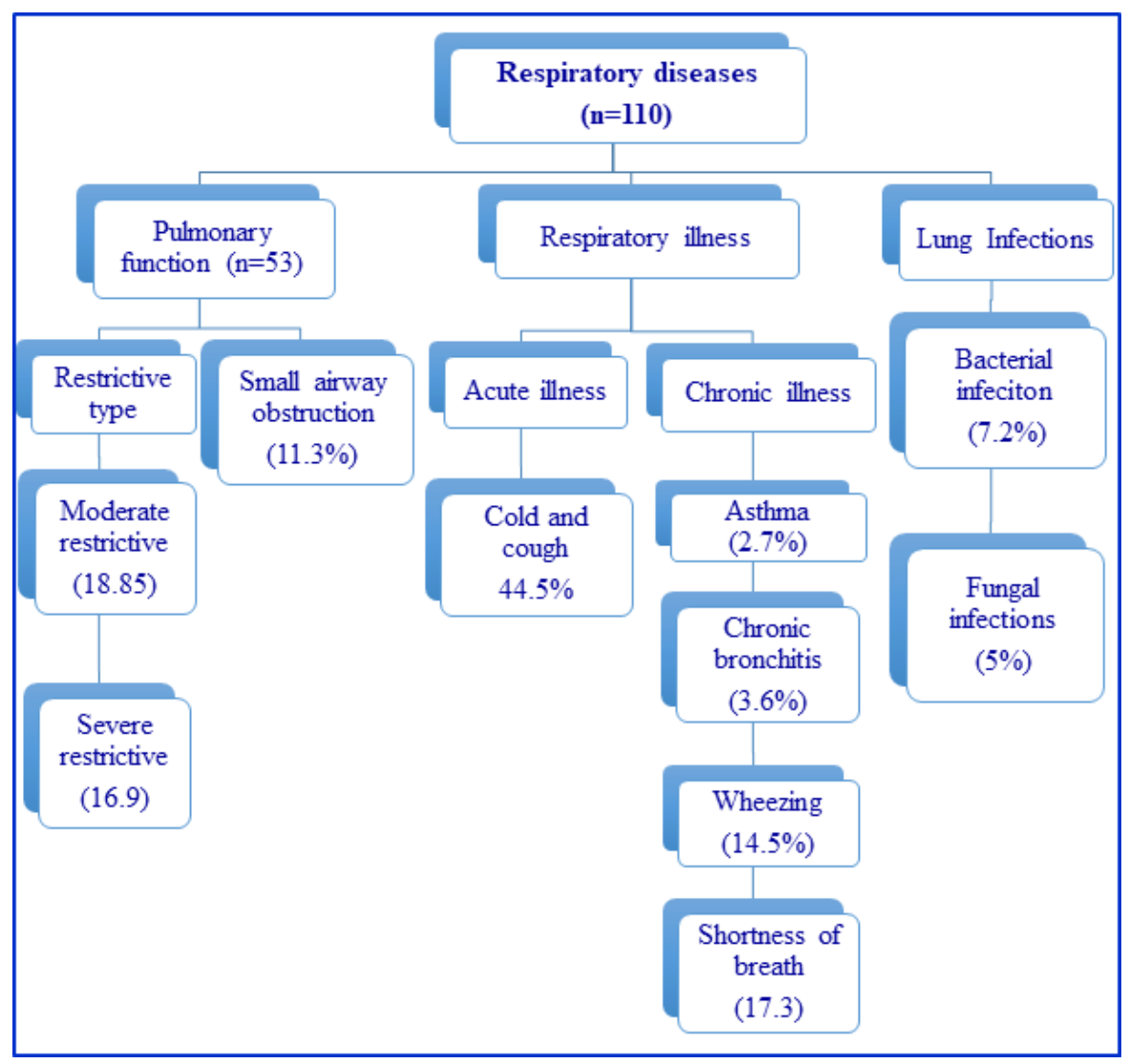

Fig 1. The illustration of respiratory diseases evaluated among the study subjects

\subsection{Pulmonary function test}

The findings of pulmonary function test were illustrated in the Figure 1. Severe restrictive, moderate restrictive and small airway obstruction in $17 \%, 19 \%$ and $11.3 \%$ were found among tannery workers respectively. The Kruskal Wallis analysis shows 
significant variations in spirometric parameters viz; FVC $(l)$, FVC $(l) \%$, FEV $1(l)$, FEV $1(l) \%$, PEFR $(l / s)$, PEFR $(l / s) \%$, and FEF 25-75 ( $\mathrm{p}<0.01$ ) among the groups (Table 3$)$. Among the three groups analysed for PFT, reduced PFT parameters were observed in pre-tanning and tanning sections than post tanning sections (Figure 2).

Table 3. The mean variations in spirometric parameters of workers among different tanning departments

\begin{tabular}{|c|c|c|c|c|c|c|}
\hline Variables & & $\mathrm{N}$ & Mean (Min-Max) & Median & $\mathrm{df}$ & $\mathrm{p}$ value $<0.05$ \\
\hline \multirow{3}{*}{ FVC (l) } & Pre tanning & 22 & $1.29 \pm .66(0.3-2.5)$ & 1.36 & \multirow{3}{*}{2} & \multirow{3}{*}{$0.008^{*}$} \\
\hline & Tanning & 18 & $1.67 \pm .64(0.6-2.9)$ & 1.60 & & \\
\hline & Post tanning & 13 & $2.08 \pm .59(1.1-3.0)$ & 2.04 & & \\
\hline \multirow{3}{*}{ FVC (1)\% } & Pre tanning & 22 & $54.05 \pm 23.9(13-90)$ & 63.50 & \multirow{3}{*}{2} & \multirow{3}{*}{$0.001^{*}$} \\
\hline & Tanning & 18 & $54.7 \pm 17.6(24-90)$ & 51.5 & & \\
\hline & Post tanning & 13 & $77.6 \pm 13(55-96)$ & 80 & & \\
\hline \multirow{3}{*}{ FEV1 (l) } & Pre tanning & 22 & $1.21 \pm 0.61(0.27-2.49)$ & 1.23 & \multirow{3}{*}{2} & \multirow{3}{*}{$0.003^{*}$} \\
\hline & Tanning & 18 & $1.59 \pm 0.62(0.58-2.78)$ & 1.53 & & \\
\hline & Post tanning & 13 & $1.97 \pm 0.59(0.86-2.94)$ & 1.98 & & \\
\hline \multirow{3}{*}{ FEV1 (l)\% } & Pre tanning & 22 & $64.2 \pm 28.8(12-100)$ & 70.5 & \multirow{3}{*}{2} & \multirow{3}{*}{$0.006^{*}$} \\
\hline & Tanning & 18 & $63.7 \pm 19.9(27-105)$ & 59.5 & & \\
\hline & Post tanning & 13 & $91.2 \pm 15.3(66-114)$ & 93 & & \\
\hline \multirow{3}{*}{$\operatorname{PEFR}(\mathrm{l} / \mathrm{s})$} & Pre tanning & 22 & $2.01 \pm 1.2(0.38-5.49)$ & 1.79 & \multirow{3}{*}{2} & \multirow{3}{*}{$0.001^{\star}$} \\
\hline & Tanning & 18 & $2.49 \pm 1.2(0.68-5.49)$ & 2.36 & & \\
\hline & Post tanning & 13 & $3.39 \pm 1.1(1.82-5.02)$ & 3.67 & & \\
\hline \multirow{3}{*}{$\begin{array}{l}\text { PEFR } \\
(1 / s) \%\end{array}$} & Pre tanning & 22 & $33.4 \pm 20.7(5-96)$ & 31 & \multirow{3}{*}{2} & \multirow{3}{*}{$0.003^{\star}$} \\
\hline & Tanning & 18 & $28.4 \pm 12.5(9-62)$ & 27.5 & & \\
\hline & Post tanning & 13 & $47.6 \pm 14(31-76)$ & 42 & & \\
\hline \multirow{3}{*}{ FEF25-75 } & Pre tanning & 22 & $1.59 \pm 0.97(0.2-3.9)$ & 2 & \multirow{3}{*}{2} & \multirow{3}{*}{$0.008^{\star}$} \\
\hline & Tanning & 18 & $2.03 \pm 1.02(0.5-4.8)$ & 2 & & \\
\hline & Post tanning & 13 & $2.78 \pm 0.89(1.6-3.9)$ & 3 & & \\
\hline \multirow{3}{*}{$\begin{array}{l}\mathrm{FEV} \\
1 / \mathrm{FVC} \%\end{array}$} & Pre tanning & 22 & $93.7 \pm 9.4(67.1-100)$ & 97.31 & \multirow{3}{*}{2} & \multirow{3}{*}{0.991} \\
\hline & Tanning & 18 & $94.9 \pm 5.7(83.9-100)$ & 98 & & \\
\hline & Post tanning & 13 & $95.6 \pm 6.4(75.4-100)$ & 97.7 & & \\
\hline
\end{tabular}

${ }^{*} \mathrm{p}$ value $<0.05$,

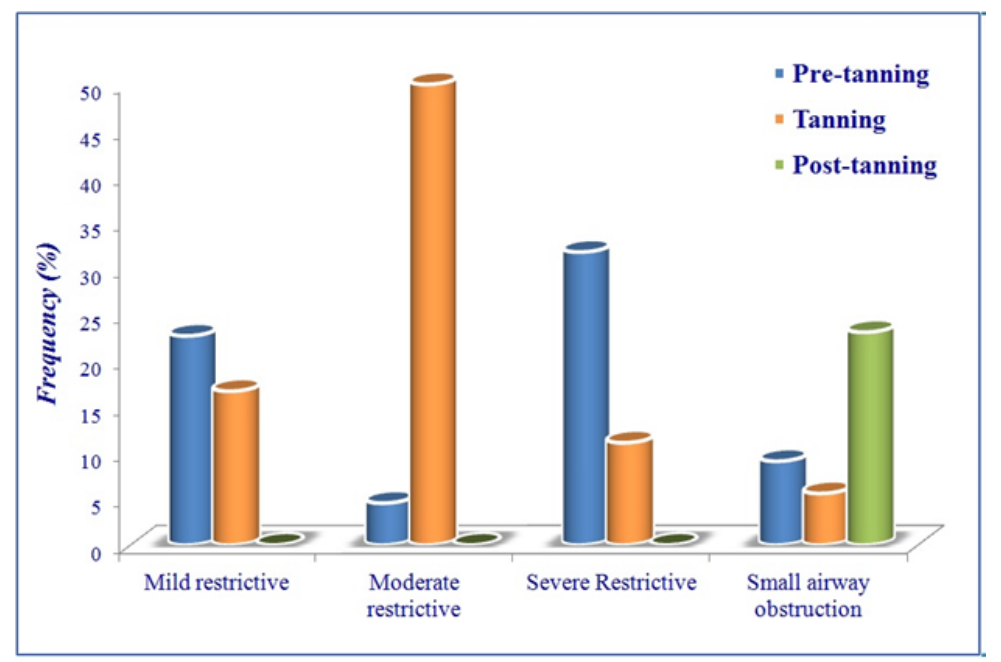

Fig 2. Findings of pulmonary function test (PFT) according to the working department of study subjects 


\subsection{Bacterial and fungal lung infections}

Bacterial and fungal lung infections were identified among 11.8\% of tannery workers (Figure 3). Ziehl neelsen stain for Mycobacterium tuberculosis showed negative. The bacterial infections viz; Klebsiella pneumonia, Streptococcus pneumonia and Staphylococcus aureus were identified from clinical samples. The fungal lung infections viz; Aspergillus niger, Aspergillus flavus and Candida albicans were identified from fungal culture. The lung infections caused by Klebsiella pneumonia were identified prominently (5\%) among study subjects. The lung infections identified were mostly among the workers engaged in pre-tanning and tanning sections.

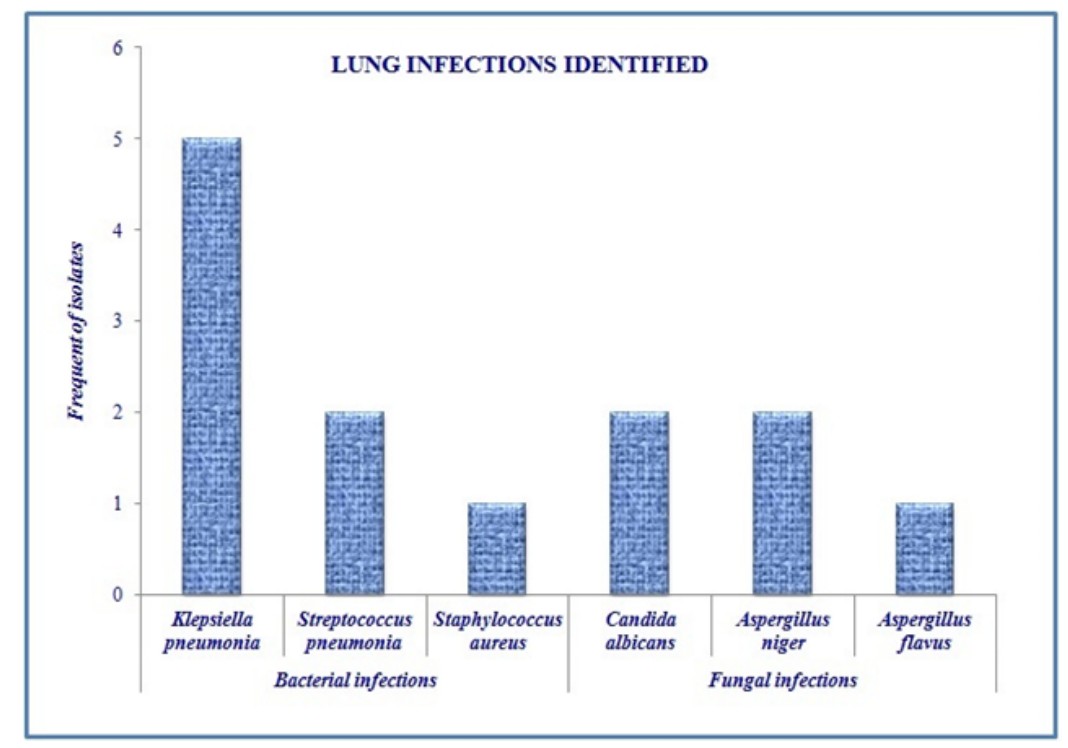

Fig 3. Lung infections identified among the study subjects and the frequent of isolates.

\subsection{Analysis of risk factors}

Binary logistic regression analysis was carried to assess the possible influence of predisposing factors viz; age, education, BMI, working sections, PPE usage, smoking, alcohol and work experience on spirometric parameters (Table 4). There was a significant association found between the working section and sprometric parameters viz; FVC\%, FEV1, FEV1 (l) \% and PEFR $(l / s) \%$ $(\mathrm{p}<0.05)$. A significant association was found between lack of PPE usage and PFT parameters viz; FVC $(l)$ and FEF 25-75\% $(\mathrm{p}<0.05)$. However, there is no significant influence in spirometric parameters by other predisposing factors.

Table 4. Binary logistic regression analysis of spirometric parameters with confounding factors

\begin{tabular}{|c|c|c|c|c|c|c|c|c|c|}
\hline Parameters & Variables & Age & BMI & Exp & Working section & $\mathrm{PPE}$ & Smoking & Alcoholic & Education \\
\hline \multirow{2}{*}{ FVC (l) } & $\beta$ & .793 & -789 & 1.051 & -.848 & 1.934 & .945 & .483 & .187 \\
\hline & $\mathrm{p}$ value & .303 & .111 & .207 & .099 & .007 & .562 & .630 & .706 \\
\hline \multirow{2}{*}{ FVC (1) \% } & $\beta$ & -1.193 & -.421 & .526 & -1.431 & .384 & -1.191 & .851 & .361 \\
\hline & $\mathrm{p}$ value & .163 & .393 & .540 & $.006^{*}$ & .595 & .462 & .385 & .451 \\
\hline \multirow{2}{*}{ FEV1 (1) } & $\beta$ & .704 & -.648 & .827 & -1.301 & 1.155 & 1.048 & .813 & .643 \\
\hline & $\mathrm{p}$ value & .920 & .177 & .329 & $.014^{\star}$ & .105 & .509 & .442 & .190 \\
\hline \multirow{2}{*}{ FEV1 (l) \% } & $\beta$ & -.172 & -.475 & -.048 & -.919 & 1.031 & 1.547 & -.574 & .476 \\
\hline & $\mathrm{p}$ value & .811 & .267 & .949 & $.048^{\star}$ & .116 & .333 & .562 & .294 \\
\hline \multirow{2}{*}{$\begin{array}{l}\text { PEFR } \\
(1 / s) \%\end{array}$} & $\beta$ & -.285 & -.088 & .686 & -1.155 & 1.233 & .710 & .751 & .151 \\
\hline & $\mathrm{p}$ value & .694 & .839 & .381 & $.017^{\star}$ & .071 & .649 & .444 & .739 \\
\hline \multirow{2}{*}{ FEF25-75 } & $\beta$ & 1.045 & -.057 & .105 & -.166 & 1.698 & .622 & -1.018 & .536 \\
\hline & $\mathrm{p}$ value & .173 & .892 & .89 & .715 & $.013^{*}$ & .700 & .276 & .261 \\
\hline FEV1/FVC & $\beta$ & -1.264 & 1.423 & 1.546 & -1.881 & 1.010 & -2.930 & -1.275 & .084 \\
\hline$\%$ & $\mathrm{p}$ value & .330 & .056 & .236 & .088 & .285 & .189 & .246 & .906 \\
\hline
\end{tabular}

${ }^{*} \mathrm{p}$ value $<0.05$ 
Tannery workers are at risk of exposure to hazardous agents at the workplace, rendering them vulnerable to occupational diseases. Almost the majority of the tannery industries in developing countries like India had fair workplace settings, which serves as a major source of health risk to the workers engaged in this sector. The employees of tannery industries exerts in unhealthy environments and are engaged in risky production processes. The safety precautions in the production process are often neglected in developing countries, due to excess in the labor force. The insecure work practice, poor hygiene and wet floor create specific hazards in the leather tanning industry. Tannery industries had five-folds higher illness rates and accidents than other occupations. The present study recorded respiratory illnesses such as asthma, chronic bronchitis, wheezing, shortness of breath and lung infections among tannery workers. Studies conducted among the tannery employees in Bangladesh, India, Indonesia, Egypt, Pakistan and Kenya had stated a high prevalence of respiratory illness and skin diseases due to occupational exposure to hazardous agents ${ }^{(11,14,22-28)}$.

The current study recorded the prevalence of respiratory illness viz; frequent cough with phlegm, dry cough, wheezing, shortness of breath and chest pain while coughing. Likewise, the abnormal respiratory symptoms such as frequent cough, wheezing, shortness of breath, sneezing attack, chest pain and respiratory tract irritation were reported among the male workers which were significantly associated with their occupational exposure to chromium and nickel ${ }^{(11,29)}$. Rastogi et al. ${ }^{(30)}$ reported a significantly higher prevalence of respiratory symptoms of dry cough and throat irritation in exposed leather tanning workers. The present study found 3\% of asthma among study subjects, which was concordant with few studies conducted among tannery workers ${ }^{(1,31)}$. Occupational exposure to chemicals, particularly chromium exposure becomes major etiological agent for occupational asthma. Kashyap et al. ${ }^{(14)}$ had stated occupational asthma, tuberculosis and chronic bronchitis among the tannery workers of Kanpur. In India increased prevalence of chronic obstructive pulmonary diseases, asthma, pneumonia and pulmonary tuberculosis may be related to elevated levels of air pollution in the industrial region ${ }^{(32)}$.

In the present study, the prevalence of severe restrictive pulmonary function and small airway obstruction was identified among the study subjects. These findings were in accordance with few other studies; those stated a high prevalence of the obstructive and restrictive type of pulmonary function among tannery workers ${ }^{(23,31)}$. The present study also recorded a significant variation in spirometric parameters viz; FVC (l), FVC (l) \%, FEV1 (l), FEV1 (l) \%, PEFR (l/s), PEFR (l/s) \%, and FEF 25-75 among the study groups. A study among tannery workers showed a significant decline in pulmonary functions FVC, FEV1, FEV1/FVC ratio, PEFR and FEF25-75 compared to control subjects ${ }^{(23)}$. A reduced FEF 25-75\%, and PEF\% was reported among exposed Egyptian tannery workers ${ }^{(26)}$. Significant reduced spirometric parameters were reported among the workers of small scale industries, those exposed to hazardous agents ${ }^{(33)}$. The tannery workers are continuously exposed to chemical compounds such as chromium, sodium sulphide, ammonium sulphate, acids, formaldehyde and organic solvents in the production process. Chromium (VI) can penetrate the cell membrane and broken down to Chromium (III) which will bind to the cellular proteins and serves as allergen ${ }^{(11)}$. Increased prevalence of respiratory symptoms and significant PFT changes may well be attributed to hexavalent chromium exposure ${ }^{(29,34)}$.

In the current study, a significant association among the risk factors of working section and lack of PPE usage with altered PFT values was noted. It was observed about $32 \%$ of workers engaged in the leather tanning process did not use any kind of PPE in the current study. The risk factors associated with work-related respiratory symptoms reported among tanners were working environment, gender, ventilation in the working section, lack of training in occupational health safety and lack of PPE usage $^{(14)}$. The other risk factors such as nature of work, chemical exposure, working hours, media exposure, education and age are the risk factors for respiratory illness among the Kanpur tannery workers ${ }^{(24)}$. Jamal et al. ${ }^{(31)}$ found a correlation between the respiratory symptoms with confounding factors of duration of exposure, ethnicity, smoking habit and nasal allergies. However, in the current study, the predisposing factors such as gender, age, working duration, smoking and alcoholism did not found to influence the spirometric parameters. A negative correlation between the duration of leather dust exposure and reduction in the PFT values were reported among tanners ${ }^{(30)}$. However, the present study was not attempted to directly correlate the respiratory symptoms with leather dust levels.

Authors could not find many studies on infectious lung diseases among tannery workers. The current study identified lung infections of Spreptococcus pneumonia, Klebsiella pneumonia, Staphlococcus aureus, Aspergillus niger, Aspergillus flavus and Candida albicans among tannery workers which can be related to occupational exposure. The Enterobacteriaceae group of bacteria (Klebsiella pneumoniae, Proteus vulgaris, E.coli, Serratia marcescens etc) and other opportunistic pathogenic groups of bacteria were isolated from the buccal mucosa of leather tanning employees of Mexico ${ }^{(35)}$, which supports the findings of the present study. The filamentous fungi of Apergillus spp, Penicillium spp, Alternaria spp, Cladosporium spp, Trichoderma spp, Fusarium spp, Aureobasidium spp, and Scopulariopsis spp were identified from the raw leathers of the tannery industry ${ }^{(12)}$. Castellanos-Arévalo et al. ${ }^{(14)}$ have reported Aspergillus fumigatus and other opportunistic pathogens as a constant biological hazard to the tannery employees because the hide serves as a medium for airborne microorganisms ${ }^{(36)}$, that leads to the development of respiratory disease contracted by inhalation. The microbial components in the indoor environment of the 
workplace, the endotoxins of Gram-negative bacteria and $\beta$-D-glucans components of molds are important respiratory tract inflammatory agents. Occupational exposure to $\beta$-D-glucans and organic dust is linked with asthma, airway inflammation, atopic allergy, nasal irritation, dry cough and farmer's lung ${ }^{(37)}$.

Lung infection caused by Klebsiella pneumonia identified among tanners carries a mortality rate of $30-50 \%$. The individuals with diabetes, aged and immunocompromised individuals have poor resistance against pneumonia infectious ${ }^{(38)}$. The current study found a prevalence of workers with diabetes $(19.9 \%)$, those workers altered immune factors may inevitable to opportunistic infections. The Aspergillus spp infections identified among the workers in the current study shows the risk of fungal exposure and the risk of opportunistic infections. The presence of airborne fungi is much more medically significant than bacteria as a source of allergy-related complications ${ }^{(35)}$. The fungal spores inhalation and associated respiratory diseases and allergic manifestations have been documented ${ }^{(18,39)}$.

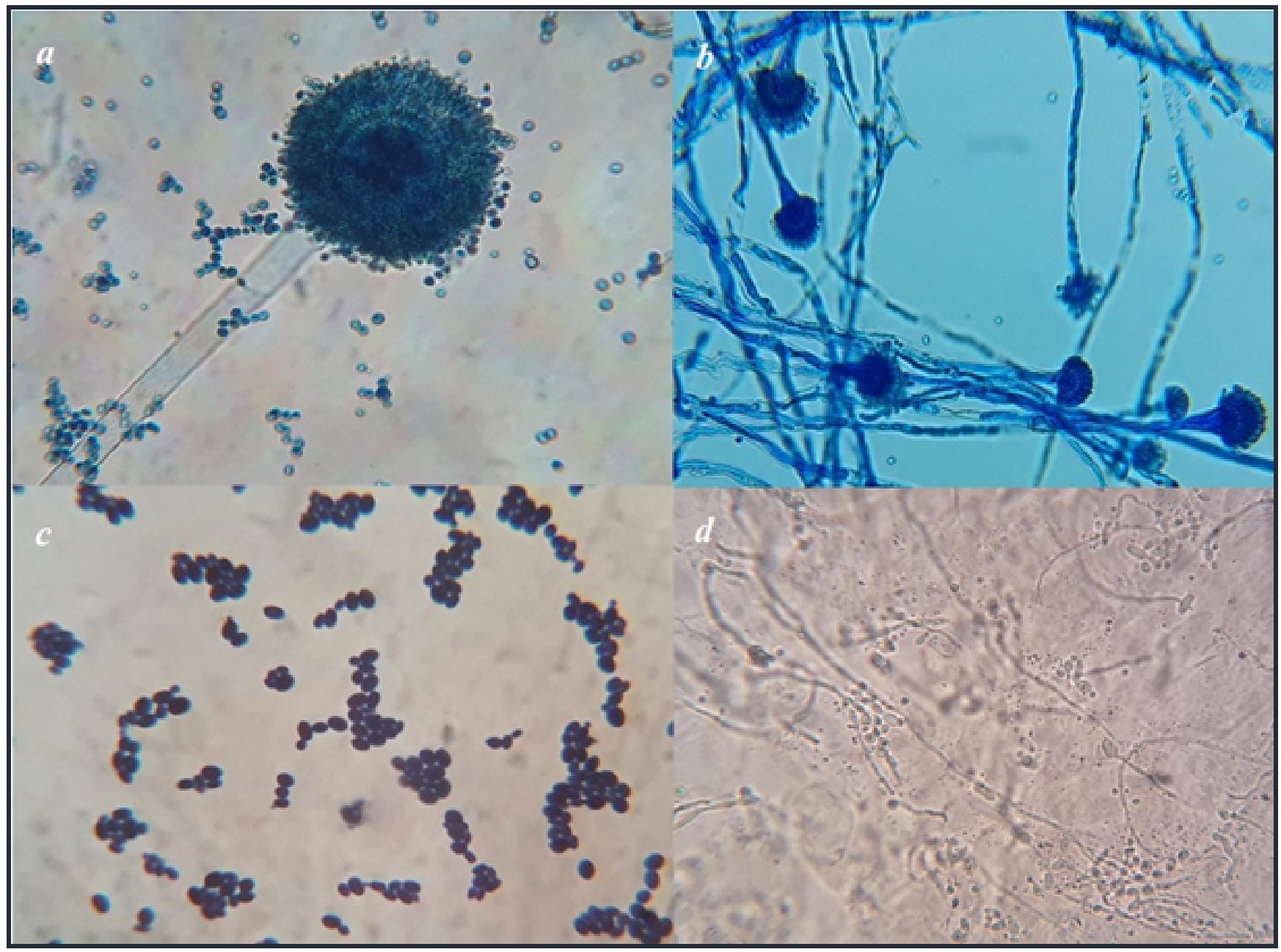

Fig 4. a \& b- LPCB mount shows Aspergillus spp. under microscopic examination (40x); c- gramstain shows budding yeast cells (100x); d$\mathrm{KOH}$ mount shows fungal filaments in a sputum sample (40x)

The leather manufacturing units use a large quantity of water to process the animal hides leading to a highly humid working environment. The environment in the pre-tanning and tanning operations are favorable for the growth of microorganisms such as bacteria and fungi. Processes like hide soaking, unhairing-liming, deliming, bating, degreasing and pickling also support microbial growth. The unprocessed animal hide has high moisture content and growth facilitating nutrients, providing an ideal environment for the rapid multiplication of microbes ${ }^{(40)}$. Hence, the pre-tanning section serves as a constant source of biological hazard to tannery workers. The humid environment with other contributing factors of elevated temperature, reduced oxygen concentration and inadequate ventilation may also facilitate the propagation of microorganisms ${ }^{(41)}$. The prevalence rate of respiratory morbidity varying depends on the working conditions. The developing countries like India the working 
environment of the workers should be improved by means of appropriate control measures to prevent the health risk emerged through their occupation.

\section{Conclusion}

The constant infectious hazards and chemical hazards at the workplace can't be neglected. Prevalent of restrictive and obstructive pulmonary function identified among tannery workers showed that the workers engaged in the leather tanning process are vulnerable to respiratory illness. Aspergillus spp and Candida spp infections identified among the workers show the risk of respiratory infections among them. Indoor bio-aerosols risk elimination, continuous biological monitoring along with workplace monitoring, educating hygiene practice, engineering controls in terms of proper ventilation to improve the indoor air quality, appropriate waste disposal and appropriate use of PPE's are mandate to curtail the respiratory morbidity among these workers.

\section{Acknowledgement}

We are thankful to the Director, ICMR-National Institute of Occupational Health, Ahmedabad for financial support. The authors are also thankful to Dr. Basavaraj, Bangalore Medical College (BMC), for his interpretations on PFT parameters. We also thank Mr. Vijay Kumar, Chennai for his contribution for clinical diagnosis. Dr. Jaseer Muhamed, Scientist-B, ROHCS for his comments on this manuscript.

\section{Conflict of interest}

The authors declare that they have no competing interests

\section{References}

1) Bepko J, Mansalis K. Common Occupational Disorders: Asthma, COPD, Dermatitis, and Musculoskeletal Disorders. American Family Physician. 2016;93(12):1000-1006.

2) International labor organization (ILO). Action towards prevention of occupational non communicable diseases. Geneva, Switzerland. 2011. Available from: http://www.worldpsi.org/sites/default/files/attachment/news/ilo_presenation.pdf.

3) World Health Organization. Global status reporton noncommunicable diseases. 2010. Available from: https://www.who.int/nmh/publications/ncd report_full_en.pdf.

4) Azom MR, Mahmud K, Yahya SM, Sontu A, Himon SB. Environmental Impact Assessment of Tanneries: A Case Study of Hazaribag in Bangladesh. International Journal of Environmental Science and Development. 2012;3:152-156. Available from: https://dx.doi.org/10.7763/ijesd.2012.v3.206.

5) Gupta VP. Tanning and Leather finishing. . Available from: https://www.iloencyclopaedia.org/part-xiv-42166/leather-fur-and-footwear/item/872tanning-and-leather-finishing.

6) Buljan J, Sahasranaman A, Hannak J. Occupational safety and health aspects of leather manufacture. Regional programme Office United Nations Industrial Development Organization. . Available from: https://leatherpanel.org/sites/default/files/publications-attachments/occupational_safety_healthe_aspects_ of_leather_manufacture.pdf.

7) Tsuchiyama T, Tazaki A, Hossain MAA, Yajima I, Ahsan N, Akhand AA, et al. Increased levels of renal damage biomarkers caused by excess exposure to trivalent chromium in workers in tanneries. Environmental Research. 2020;188. Available from: https://dx.doi.org/10.1016/j.envres.2020.109770.

8) Engwa GA, Ferdinand PU, Nwalo FN, Unachukwu MN. Mechanism and Health Effects of Heavy Metal Toxicity in Humans, Poisoning in the Modern World - New Tricks for an Old Dog?, OzgurKarcioglu and BanuArslan, IntechOpen. 2019. Available from: https://doi.org/10.5772/intechopen.82511.

9) Islam LN, Rahman F, Hossain A. Serum Immunoglobulin Levels and Complement Function of Tannery Workers in Bangladesh. Journal of Health and Pollution. 2019;9(21). Available from: https://dx.doi.org/10.5696/2156-9614-9.21.190308.

10) Were F, Moturi C, Kamau G, Wafula G. Respiratory diseases due to occupational exposure to nickel and chromium among factory workers in Kenya. Journal of Community Medicine \& Health Education. 2013;3:1-7. Available from: https://doi.org/10.4172/2161-0711.1000252.

11) Febriana SA, Jungbauer F, Soebono H, Coenraads PJ. Inventory of the chemicals and the exposure of the workers' skin to these at two leather factories in Indonesia. International Archives of Occupational and Environmental Health. 2012;85(5):517-526. Available from: https://dx.doi.org/10.1007/s00420011-0700-1.

12) Işsever H, Özdilli K, Özyildirim BA, Hapçioglu B, ince N, ince H, et al. Respiratory Problems in Tannery Workers in Istanbul. Indoor and Built Environment. 2007;16(2):177-183. Available from: https://dx.doi.org/10.1177/1420326x06076670.

13) Dalju I, Dessie A, Bogale L, Mekonnen TH. Occupational risk factors associated with respiratory symptoms among tannery workers in Mojo town. Multidisciplinary Respiratory Medicine. 2019;14. Available from: https://doi.org/10.1186/s40248-019-0188-1.

14) Kashyap GC, Sharma SK, Singh SK. Prevalence and predictors of asthma, tuberculosis and chronic bronchitis among male tannery workers: A study of Kanpur City, India. Clinical Epidemiology and Global Health. 2020. Available from: https://doi.org/10.1016/j.cegh.2020.07.002.

15) Castellanos-Arévalo AP, Camarena-Pozos DA, Castellanos-Arévalo DC, Rangel-Córdova AA, Peña-Cabriales JJ, Arévalo-Rivas B, et al. Microbial contamination in the indoor environment of tanneries in Leon, Mexico. Indoor and Built Environment. 2016;25(3):524-540. Available from: https: //dx.doi.org/10.1177/1420326x14564798.

16) Hong PY, Li X, Yang X, Shinkai T, Zhang Y, Wang X, et al. Monitoring airborne biotic contaminants in the indoor environment of pig and poultry confinement buildings. Environmental Microbiology. 2012;14:1420-1431. Available from: https://doi.org/10.1111/j.1462-2920.2012.02726.x. 
17) Kim KH, Kabir E, Jahan SA. Airborne bioaerosols and their impact on human health. Journal of Environmental Sciences. 2018;67:23-35. Available from: https://dx.doi.org/10.1016/j.jes.2017.08.027.

18) Esmaeili S, Naddaf SR, Pourhossein B, Shahraki AH, Amiri FB, Gouya MM, et al. Seroprevalence of Brucellosis, Leptospirosis, and Q Fever among Butchers and Slaughterhouse Workers in South-Eastern Iran. PLOS ONE. 2016;11(1). Available from: https://dx.doi.org/10.1371/journal.pone.0144953.

19) Wiszniewska M, Walusiak-Skorupa J, Pannenko I, Draniak M, Palczynski C. Occupational exposure and sensitization to fungi among museum workers. Occupational Medicine. 2009;59(4):237-242. Available from: https://dx.doi.org/10.1093/occmed/kqp043.

20) Delaney A. Barriers to Grievance: Leather Footwear Workers in Tamil Nadu, South India. 2016; Non-Judicial Redress Mechanisms Report Series 12. 2016.

21) Mahon CR, Lehman DC. Textbook of Diagnostic Microbiology. Sixth ed. and others, editor. .

22) Hasan MDM, Hosain S, Asaduzzaman AM, Haque MA, Roy UK. Prevalence of Health Diseases among Bangladeshi Tannery Workers and associated Risk factors with Workplace Investigation. Journal of Pollution Effects \& Control. 2016;04(04):175-175. Available from: https://dx.doi.org/10.4172/23754397.1000175.

23) Chandrasekaran V, Dilara K, Padmavathi R. Pulmonary functions in tannery workers - a cross sectional study. Indian Journal of Physiology and Pharmacology. 2014;58(3):205-209.

24) Gangopadhyay S, Ara T, Dev S, Ghoshal G, Das T. An Occupational Health Study of the Footwear Manufacturing Workers of Kolkata, India. Studies on Ethno-Medicine. 2011;5(1):11-15. Available from: https://dx.doi.org/10.1080/09735070.2011.11886386.

25) Karunamoorthy P, Mani RE, Ravichandran B, Venugopal D, Ambikapathy M, Kondhalkar SJ. Prevalence of Occupational Skin Diseases and its Predisposing Factors in Leather Tanning Workers of Southern India. Current World Environment. 2020;15(3):487-501. Available from: https://dx.doi. org/10.12944/cwe.15.3.13.

26) Younis F, Rasoul GA, Salem MA, Allam H, Kasemy Z. Health-related disorders on occupational exposure to chromium in a leather tanning factory (Menoufia, Egypt). Menoufia Medical Journal. 2017;30(1). Available from: https://dx.doi.org/10.4103/1110-2098.211508.

27) Afify M, Arafa A, Maksoud N. Evaluation of some health hazards among Egyptian leather tannery workers. Journal of Applied Science and Research. 2013;9(4):2959-2964.

28) Shahzad K, Akhtar S, Mahmud S. Prevalence and determinants of asthma in adult male leather tannery workers in Karachi, Pakistan: A cross sectional study. BMC Public Health. 2006;6(1). Available from: https://dx.doi.org/10.1186/1471-2458-6-292.

29) Stern FB, Beaumont JJ, Halperin WE, Murthy LI, Hills BW, Fajen JM. Mortality of chrome leather tannery workers and chemical exposures in tanneries. Scandinavian Journal of Work, Environment \& Health. 1987;13(2):108-117. Available from: https://dx.doi.org/10.5271/sjweh.2073.

30) Rastogi S, Pandey A, Tripathi S. Occupational health risks among the workers employed in leather tanneries at Kanpur. Indian Journal of Occupational and Environmental Medicine. 2008;12(3). Available from: https://dx.doi.org/10.4103/0019-5278.44695.

31) Asad J, Atif M, Fehmida K, Tuula P, Heikki S, Jyrki L. Prevalence of Respiratory Symptoms, Bronchial Asthma and Obstructive Lung Disease among Tannery Workers. Annals of Environmental Science and Toxicology. 2018;2(1):033-042. Available from: https://dx.doi.org/10.17352/aest.000010.

32) Kashyap GC, Puri P, Singh SK. Respiratory Health Upshots due to Contaminated Living Environment: A Cross-Sectional Study of the Industrial Belt of Kanpur City. India Socio Economic Challenges. 2020;4(1):5-12. Available from: https://doi.org/10.21272/sec.4(1).5-12.2020.

33) Ahmada I, Balkhyourb M. Occupational exposure and respiratory health of workers at small scale industries. Saudi Journal of Biological Sciences. 2020;27(3):985-990. Available from: https://doi.org/10.1016/j.sjbs.2020.01.019.

34) Neghab M, Azad P, Honarbakhsh M, Zarei F, Ghaderi E. Acute and Chronic Respiratory Effects of Chromium Mists. Journal of Health Sciences \& Surveillance System. 2015;3(3):119-124.

35) Castellanos-Arévalo AP, Camarena-Pozos DA, Castellanos-Arévalo DC, Rangel-Córdova AA, Peña-Cabriales JJ, Arévalo-Rivas B, et al. Microbial contamination in the indoor environment of tanneries in Leon, Mexico. Indoor and Built Environment. 2016;25(3):524-540. Available from: https: //dx.doi.org/10.1177/1420326x14564798.

36) Mandal J, Brandl H. Bioaerosols in indoor environment e a review with special reference to residential and occupational locations. The Open Environmental \& Biological Monitoring Journal. 2011;4:83-96. Available from: https://doi.org/10.2174/1875040001104010083.

37) Lawniczek-Walczyk A, Górny RL, Golofit-Szymczak M, Niesler A, Wlazlo A. Occupational exposure to airborne microorganisms, endotoxins and $\beta$ glucans in poultry houses at different stages of the production cycle. Annals of Agricultural and Environmental Medicine. 2013;20(2):259-268.

38) Ashurst JV, Pneumonia DAK. Klebsiella Pneumonia. In: StatPearls . Treasure island, Florida. Stat Pearls Publishing. 2020.

39) Skóra J, Gutarowska B, Stepień L, Otlewska A. Pielech-Przybylska K. The Evaluation of Microbial Contamination in the Working Environment of Tanneries. Medycyna Pracy. 2014;65(1):15-32. Available from: https://doi.org/10.13075/mp.5893.2014.005.

40) Orlita A. Microbial biodeterioration of leather and its control: a review. International Biodeterioration \& Biodegradation. 2004;53(3):157-163. Available from: https://dx.doi.org/10.1016/s0964-8305(03)00089-1.

41) Brown GS, Mohr AJ. Fate and transport of microorganisms in air. In: CJ H, editor. Manual of environmental microbiology. Washington. ASM Press. 2002;p. 827-865. Available from: https://doi.org/10.1128/9781555818821.ch3.2.4. 